\title{
Influence of Hydrodynamic Cavitation on Rheological and Transportable Properties Viscous Crude Oils
}

\begin{abstract}
V. H. Nurullayev
Candidate of Technical Sciences, State Oil Company of the Azerbaijan Republic (SOCAR) Engineer of «Quality Control»

Department 28 Khodzhala ave., Baku, Az 1025

Republic of Azerbaijan

\section{B. T. Usubaliyev}

Doctor of Chemical Sciences Azerbaijan State Oil and Industry University. Research Institute of

"Geotechnical problems of oil, gas and chemistry", Azerbaijan, Baku, 225, D.Alieva.

\author{
G. G. Ismayilov \\ Doctor of Technical Sciences \\ Professor of «Oil and gas transportation and \\ storage» Department, 225, D. Alieva, Baku \\ Republic of Azerbaijan
}

Azerbaijan State University of Oil and Industry

\section{S. T. Aliyev}

Graduate student, Azerbaijan State University of Oil and Industry, Graduate student of «Oil and gas transportation and storage» Department, 225 D. Alieva, Baku, Republic of Azerbaijan

Abstract: The article presents the results of theoretical and experimental studies on the mechanical activation of viscous oil, which confirmed the effectiveness of cavitation on their rheological properties.The major making source of raw materials of oil branch stocks heavy and bituminous crude oils are. Improvement of technologies transportations it is, caused by their high resource potential. Considering problem urgency, from our party experiences on influence studying cavitation on formation asphaltene - pitch - paraffin adjournment on an internal surface of the pipeline have, been spent. The possibility of an intensification of process of influence of chemical reagent by cavitation for decrease in viscosity of oil is established. Results of pilot studies on complex influence of chemical reagents and cavitation on viscosity crude oil with various structural and group structure are received.
\end{abstract}

As have shown experiments, as a result cavitation in oil there are irreversible changes of viscosity, pressure of sated steams, shares: paraffin, asphaltene and pitch hydrocarbons.

Keywords: Cavitation, asphaltene, high-paraffinic, oil transport, toluene, crude oil.

\section{INTRODUCTION}

In recent years, Azerbaijan becomes more and more important player in the world market of energy resources. Having the largest explored reserves of crude oil near the Caspian Sea. Characteristic of modern oil production is increase in world structure of raw material resources of a share of hardly removable stocks. Due to the tendency of exhaustion of stocks of lungs, crude oil interest in hardly removable crude oils has increased in the world. Production of the majority of fields of Azerbaijan are viscous and high-paraffinic crude oil. Viscosity such high-viscosity crude oil at fall of temperature increases to such an extent that they become non transportable [1-3]. At transport high-paraffinic the intensive parafinization of pipelines, decrease in their capacity occurs crude oil that considerably complicates operation and leads to growth of labor and material inputs. The existing ways of impact on rheological properties viscous crude oil and oil products not fully satisfy consumers because of their low energy efficiency and low reliability. Therefore scientists and designers intensive search of new ways of their transportation and creation the power effective of designs of devices of impact on rheological properties of viscous liquids with application of the new, earlier not studied physical phenomena continues [4-5]. On this subject in the press and Internet resources there are numerous publications on developments of highly effective devices which often have disputable results. Their analysis allows to allocate the ways of impact on the rheological properties of viscous liquids applicable which are most acceptable, in our opinion, in practice.

Mechanical influence: The easiest way of decrease in static and dynamic stress of shift and by that decrease in hydraulic losses at transfer is mechanical impact on oil with destruction of a crystal 


\section{H. Nurullayev et al.}

paraffin grid. However, it is necessary to notice that machining is effective in a certain area of temperatures when the connected crystals of paraffin create a branched lattice. Work of the mechanical grinders based on impact of the processed liquid about a surface of elements of a grinder thanks to presence of relative speeds causes emergence of a high gradient of pressure, promotes emergence in liquid of wave processes. When crushing impurity very convincing results are received, however, such devices for improvement of rheological properties of oil aren't tested yet. Spend researches from a crude oils have shown that mechanical impact on the paraffin structures which are formed in oil considerably lower durability of secondary structures, reduces temperature of their hardening, viscosity, static and dynamic tension of shift. At the particular conditions mechanical impact on crude oil it is possible to achieve that it loses the non-Newtonian properties and becomes the Newtonian. According to processing can provide with mechanical grinders considerable improvement of rheological properties of oil. As a rule, they not power-intensive. However for their broad industrial application additional experimental works are required [6-7].

\section{Materials AND MethodS}

Processing by cavitation. In recent years interest on direct transformation of mechanical energy in thermal in so-called "hydrodynamic heaters of liquid" (HHL) or "vortex heatgenerators" (VTG) has increased. According to conclusions of authors, heating of liquid in them happens as at the expense of the hydrodynamic, and cavitational phenomena. Their principle of action is often similar to such devices, already widely known in equipment, as a hydrobrake or the hydrocoupling. Cavitation, in a general sense words, is understood as emergence in drop liquid of areas (cavities) filled with vapors and gases emitted from liquid. Cavitation belongs to the non-stationary phenomena and happens when absolute pressure falls in some area of drop liquid below some critical value of $\mathrm{P}_{\text {kav }}$ at which there is a rupture of a continuity of a stream and the cavities filled with vapors or gases are formed. At advance of a stream to the area of an elevated pressure (according to Bernoulli's equation, area of falling of speed of a stream) there is a interlocking (condensation) of gas bubbles leading to blows of particles of liquid the friend about the friend and also walls. The positive effect from cavitation is an obtaining fine monotonous mass of liquid, i.e. crushing of paraffinic educations in oil. One of features of cavitational process when pumping oil - significant influence of thermodynamic properties of oil. It is well visible on the example of expansion of initial bubbles at steam cavitation. In case of existence of a steam cavity (a subcavity we will accept in this case the cavity in the form of a bubble filled with steam) cavitation is provided with the continuous process of evaporation coming at a heat transfer from a cavity wall. As sources of heat are absent, it is supposed that heat, necessary for evaporation, is selected from the liquid surrounding a cavity [8-9]. Local self-cooling of the liquid surrounding a cavity at formation of cavitational bubbles can significantly reduce pressure of vapors of oil in a cavity. Besides thermodynamic properties, cavitation emergence intensity of her development are influenced pressure of saturated steam of oil, the steepness of curve dependence of pressure of saturated steam of oil on temperature, by viscosity, a superficial tension, amount of the dissolved and free gas, time of stay of oil in a zone with the lowered pressure, character of a stream (laminar or turbulent), etc. Dependence of a critical cavitational stock of any element of hydraulic system on change viscosity of oil can have double character. First, forces of viscosity of oil slow down the growth rate of a cavitational bubble and by that interfere with development of cavitational process. Besides, in some cases viscosity of the pumped-over oil can alter an diagrams of speeds of flowing part of canals and, thereby, reduce extent of depression of a stream, i.e. also "tighten" the beginning of cavitation. Secondly, viscosity leads to increase in hydraulic resistance on a site from an entrance to a hydraulic element, to places of the minimum pressure that finally accelerates approach of the cavitational mode. Shows results of researches that growth of bubbles in oil significantly more slowly, than in ideal liquid. Viscosity of oil exerts considerable impact on growth of a bubble.

It should be noted that despite abundance of experimental works, more or less satisfactory theoretical settlement techniques of the effects arising in HHL and VTG from the point of view of classical aerodynamics and hydrodynamics still aren't available. There are also numerous works in which their incredibly high efficiency (which is often exceeding 100\%) is noted. The impossibility to explain process from the point of view of traditional physics has led to the fact that the vortex power system was strongly, proved in the list of the "pseudoscientific" directions. Meanwhile, developments of working models of the HHL and VTG installations realizing the principle described above are already widely presented at the market. At present time for territories of Russia, some republics of the former 
Soviet Union and a number of foreign countries hundreds of vortex heat generators of various power made by a number of the domestic scientific and production enterprises successfully function [10-11].

So, according to authors of development of VTG use of VTG for processing of oil leads to the following results:

1. Cavitation accelerates diffusion of oil in a paraffin cavity, intensifies process of his destruction. Acceleration of dissolution of paraffin happens for cчèт intensifications of hashing of oil on border oil-paraffin and actions of impulses of pressure which as if spray paraffin particles.

2. Oil doesn't possess the viscosity submitting to laws of Newton, Poiseuille, Stokes as the long randomly located molecules of paraffin and pitches form some flexible lattice in which solution settles down. Therefore the system renders considerable resistance to shift forces. Cavitation breaks off a continuous chain, destroying communications between separate parts of molecules. These communications are rather small therefore insignificant influence is necessary.

3. After the termination of influence of a molecule of paraffin and pitches, slowly restore initial system thanks to random Brownian motion. However when processing oil by the cavitational field the final product is stable not less than 60 days. The analysis of researches shows that under the influence of the cavitational field the $\mathrm{C}-\mathrm{C}$ communications in paraffin molecules are broken owing to what there are changes of physical and chemical structure: reduction of molecular weight, crystallization temperature, etc.

4. Cavitation influences change of structural viscosity, i.e. a temporary break-up of Van-der-vaals of communications. Irreversible reduction of viscosity of oil takes place after oil radiation by the cavitational field this effect is, gained for one pass through the VTG installation. The vortex VTG110 heat generator makes heating of oil with simultaneous change structures that reduces load of the crude oil pipeline and costs of crude oil pumping [12-15].

To category of the most effective receptions improving rheological properties viscous nefty and oil products, it is necessary to carry complex methods of influence, for example combination of introduction of solvent or reagent and cavitational processing of oil that will allow to increase the gained effect of every way separately.

\section{RESUlTS AND DISCUSSION}

Justification of the choice of the modes of processing of oil, the choice of chemical reagents is given, experiment planning is carried out, variation intervals are set, pilot studies of process of decrease in viscosity of oil under the influence of cavitation with use of reagents are described explanations of results of experiments are provided. For definition of effect of application of cavitation for the purpose of decrease in viscosity of oil experiments on three, various the crude oils with different structural and group structure and physic mechanical characteristics have been, made. For experiments have been selected paraffinic oil of the field Shikhbagi, Bulla-deniz and resinous oil of the field Shirvan (tab.). The picked-up samples of crude oil allow to conduct researches in the wide range high-viscosity crude oil.

Table1. Structural and group structure investigated by crude oils

\begin{tabular}{|l|l|l|l|l|}
\hline \multirow{2}{*}{ Crude oil field } & \multirow{2}{*}{$\begin{array}{l}\text { Kinematic viscosity } \\
\text { at } 20^{\circ} \mathrm{C}, \mathrm{sSt}\end{array}$} & Contents, \% of masses. & Asphaltene \\
\cline { 3 - 5 } & 32,53 & Paraffin & Pitch & 2,69 \\
\hline Shikhbagi & 11,21 & 9,7 & 5,9 & 0,28 \\
\hline Bulla-deniz & 79,86 & 3,88 & 13,27 & 6,24 \\
\hline Shirvan & 83,42 & 6,21 & 18,32 & 4,86 \\
\hline Muradkhanli & &
\end{tabular}

For determination of rational parameters of cavitational processing of oil a series of experiments with processing of oil at various intensity during different periods has been, carried out (fig. 1). 


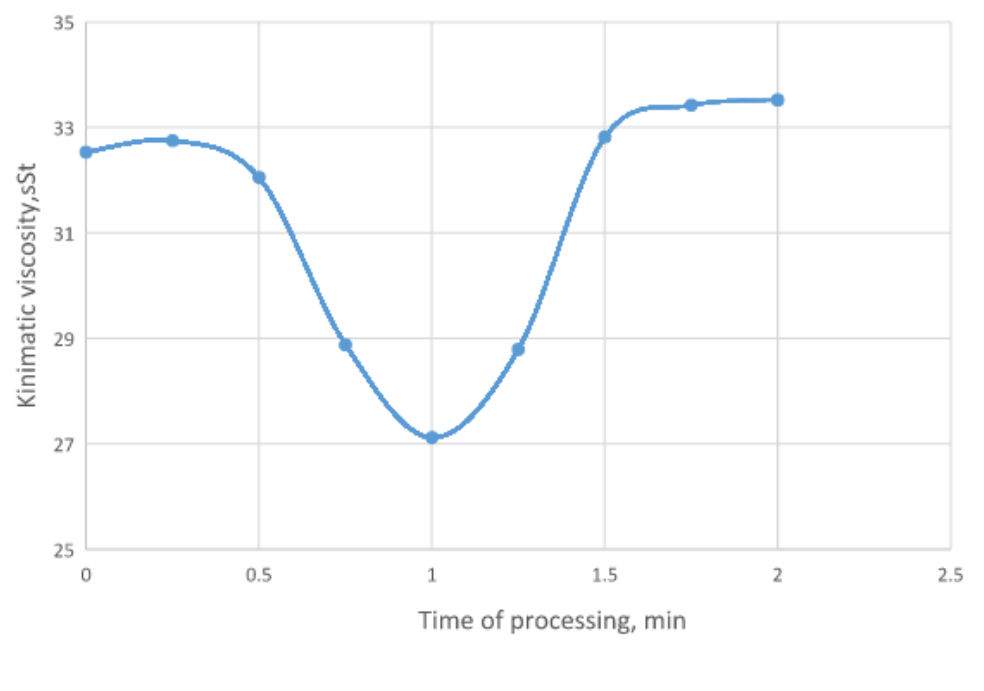

Fig1. Change of kinematic viscosity of crude oil of the field Shikbagi depending on test processing time

Further a series of experiments for selection of reagent and its concentration has been carried out. Results of experiments are given in the histogram (fig. 3). The best results have been received at introduction to crude oil of a xylene and a butilatsetat. So, introduction of $2 \%$ of masses. a xylene butylacetate introduction - for $23 \%$ has allowed to reduce viscosity of crude oil by $27 \%$, and. The subsequent measurements of viscosity of samples of oil in 24,48 and 72 hours have shown that growth of viscosity of oil after introduction of reagent doesn't exceed 5-7\%.

Further a series of experiments on research of process of complex processing of oil by reagent and cavitation with use of the parameters of processing received in the previous series of experiment has been carried out (fig.2).

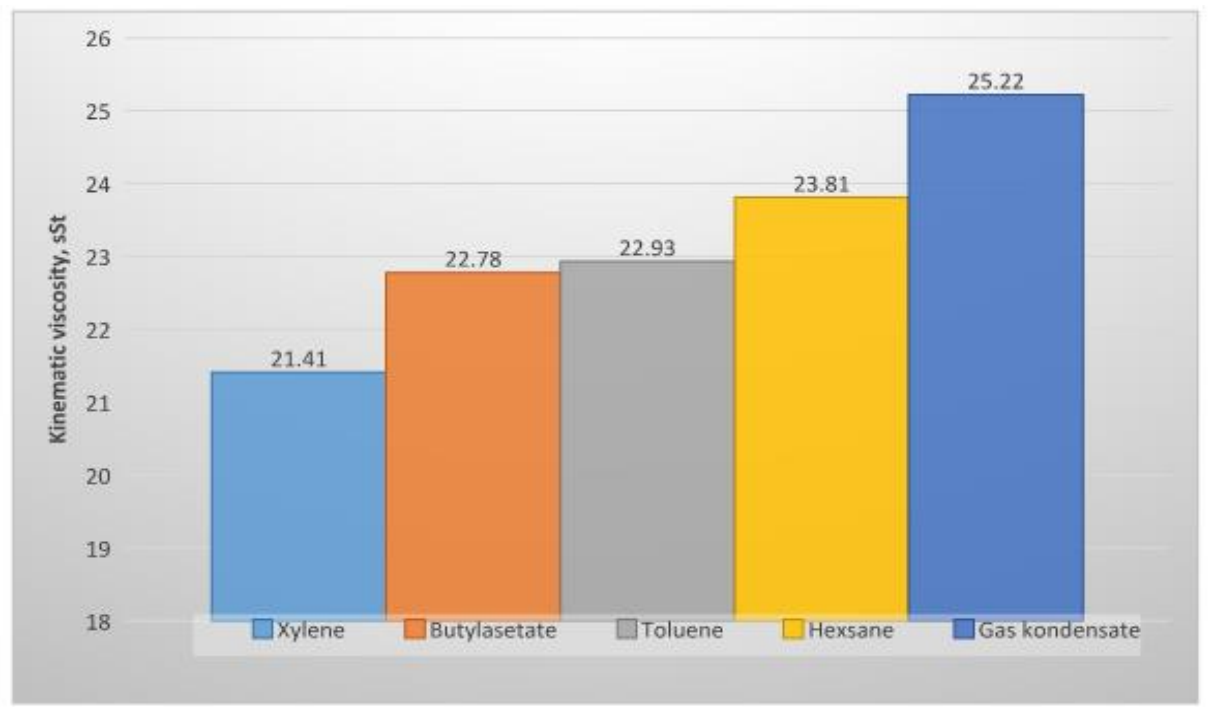

Fig2. Change of kinematic viscosity of oil of the field Shikbagi after introduction of $2 \%$ of mass. reagent

For studying of process of complex influence of reagent and cavitation on field oil Shikbagi it is necessary to compare the data obtained before cavitational processing. The corresponding schedules of dependence of dynamic viscosity of oil from relaxation time have been for this purpose constructed.

Experiments have shown that complex influence of reagent and cavitation considerably reduces viscosity of initial crude oil in comparison with influence only of reagent. The additional effect of 
decrease in viscosity due to cavitational processing has made $25-35 \%$ depending on the applied reagent. The best result at complex influence was shown by a series of experiments with a xylene and toluene. So, at introduction of $2 \%$ of mass. a xylene and crude oil processing viscosity of crude oil has decreased by $44 \%$, at introduction of toluene and similar influence, viscosity of crude oil has decreased by $37 \%$ (fig. 3 ).

The subsequent measurements of viscosity of samples in 24,48 and 72 hours have shown that growth of value of viscosity after complex processing is characteristic of field oil Shikbagi. Depending on the applied reagent dynamic viscosity of oil has increased for $25-35 \%$.

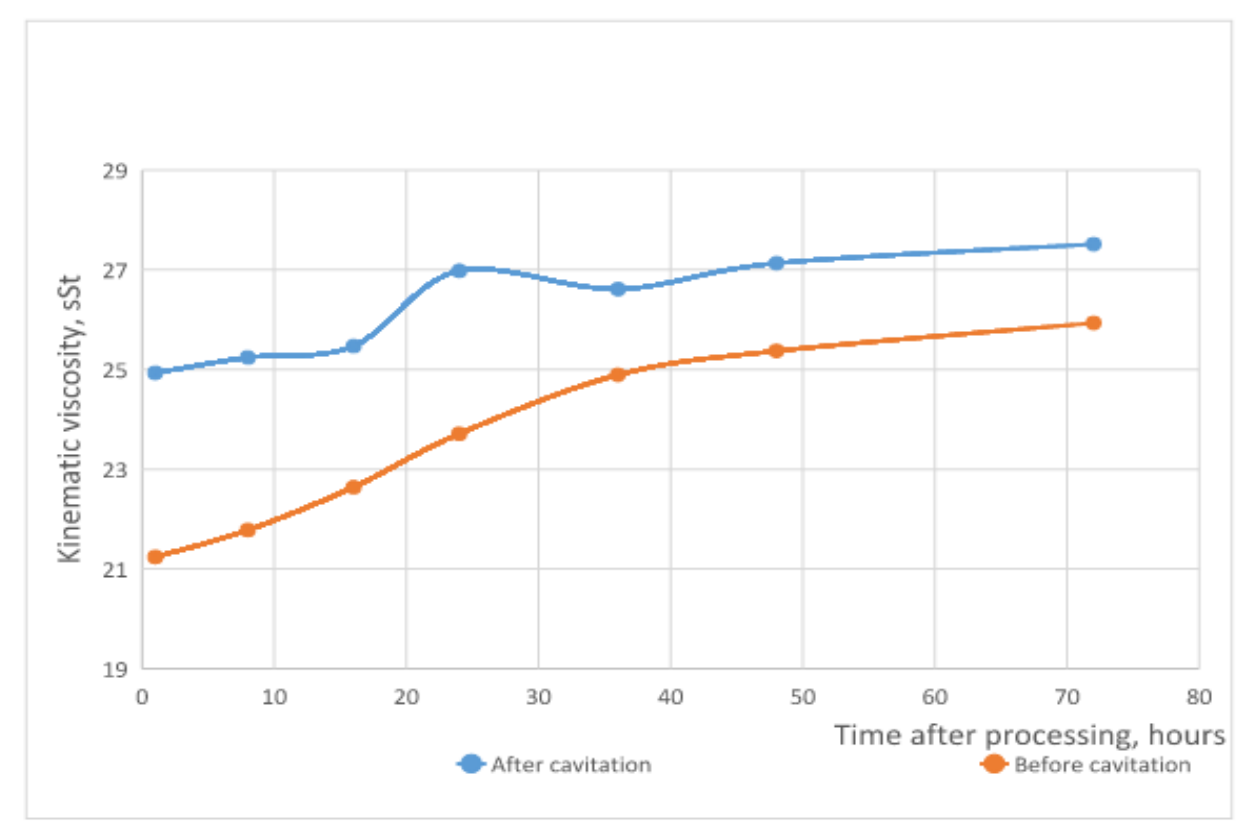

Fig3. Change of kinematic viscosity of oil of the field of Shikbagi from a test storage time after introduction of $2 \%$ of masses. toluene and hashing: 1-without cavitational processing; 2-after cavitational processing

For crude oil of the field Bulla-deniz the following parameters of processing have been picked up: intensity, frequency of fluctuations, processing time (fig.4).

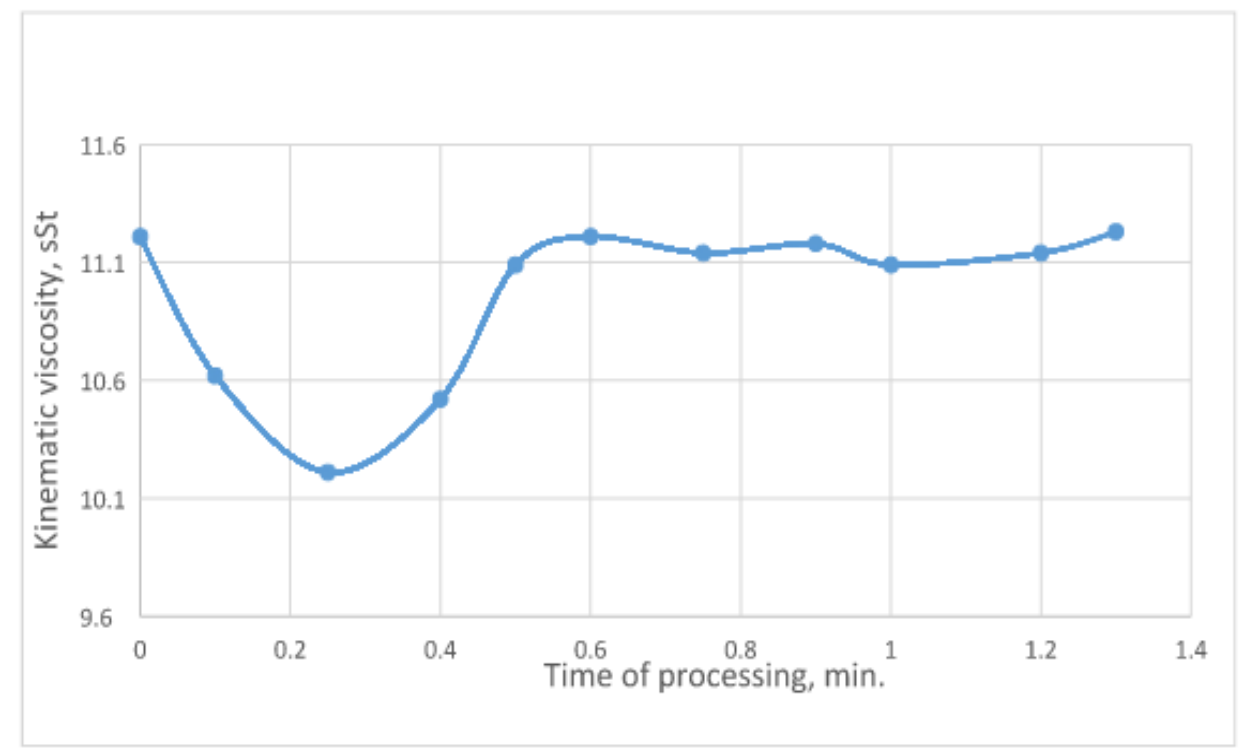

Fig4. Change of kinematic viscosity of crude oil of the field Bulla-deniz in dependence on test processing time.

Results of a series of experiments on selection of reagent and its concentration are given in the histogram (fig. 7). The best results have been received at introduction to butylacetate crude oil. So, introduction of $2 \%$ of masses. butylacetate has allowed to reduce viscosity of oil by $29 \%$. The subsequent in 24, 48 and 72 hours have shown that growth of viscosity of oil after introduction of reagent doesn't exceed $10-12 \%$ (fig.5). 


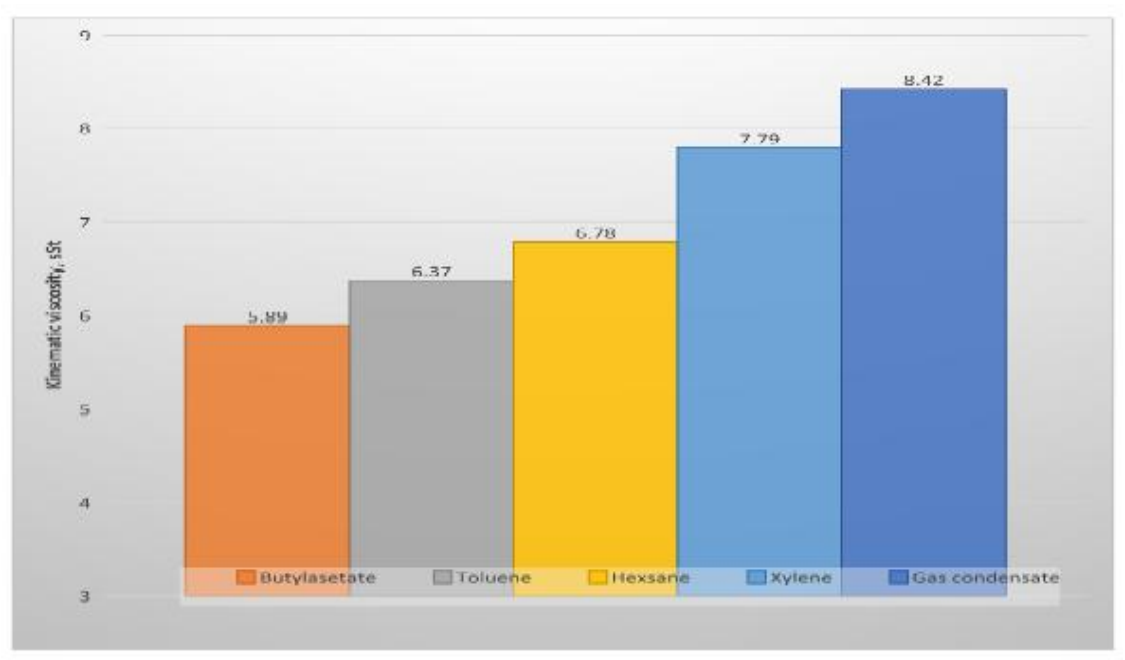

Fig5. Change of kinematic viscosity of oil of the field Bulla-deniz after introduction of $2 \%$ of mas. reagent

Further a series of experiments by definition of effect of complex processing of oil of the field Bulladeniz by reagent and cavitation with use of the parameters of processing received in the previous series of experiment has been, carried out (fig.6).

Experiments have shown that complex influence of reagent and cavitation considerably reduces viscosity of oil of the field Bulla-deniz in comparison with influence only of reagent. The additional effect of decrease in viscosity due to cavitational processing has made $17-19 \%$. The best result at complex influence was shown by a series of experiments with butyl acetate. So, at introduction of $2 \%$ of masses. butylacetate and oil processing, viscosity has decreased by $42 \%$ (fig.6).

The subsequent measurements of viscosity of samples in 24, 48 and 72 hours have shown that growth of value of viscosity after complex processing is characteristic of field crude oil Shikbagi. Depending on the applied reagent dynamic viscosity of crude oil has increased for 11-20\%.

Thus, experiments have shown that field Bulla-deniz oil, unlike field oil Shikbagi, keeps the rheological properties after complex processing better.

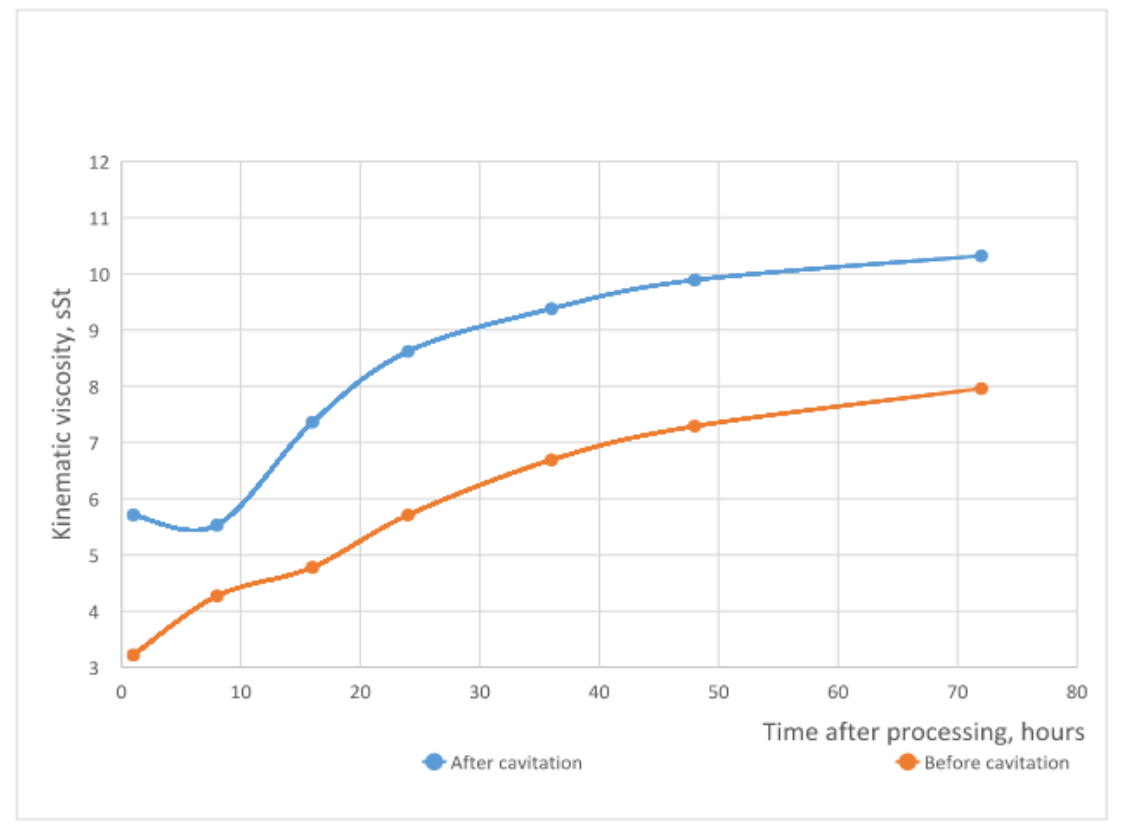

Fig6. Change of kinematic viscosity of oil of the field Bulla-deniz from a test storage time after introduction of $2 \%$ of masses. butylacetate and hashing: 1 - without cavitational processing; 2 -after cavitational processing

Results of experiments on complex processing of crude oil of the field Shirvan reagent and cavitation have shown that this crude oil, unlike paraffinic crude oil fields Bulla deniz and Shikbagi is more weakly subject to impact of cavitation. For crude oil of the field Shirvan the following parameters of processing have been picked up: intensity, frequency of fluctuations, processing time (fig.7). 


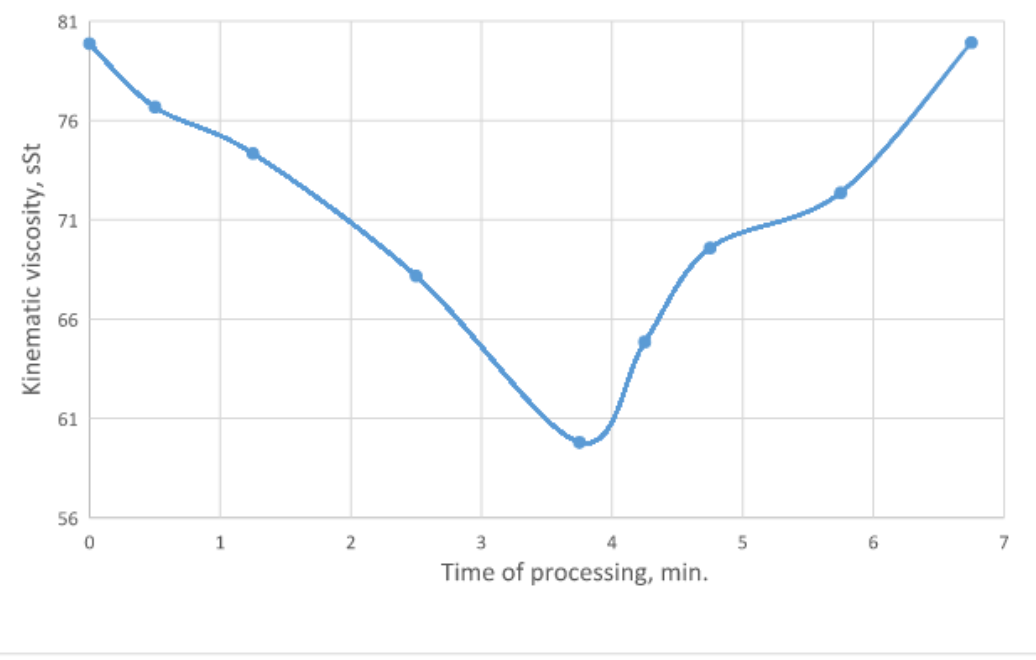

Fig7. Change of kinematic viscosity of crude oil of the field Bulla-deniz in dependence on test processing time.

The additional effect of decrease in viscosity due to cavitational processing has made $2-3 \%$ in comparison with influence of reagent (fig.8).

On the basis, of the made experiments the following regularities have been revealed: cavitational processing influences rheological characteristics of oil differently, depending on intensity and duration of influence. The greatest effect of decrease in viscosity of oil is, gained at intensity of processing. Paraffinic oil are better subject to processing, than resinous. The greatest effect of introduction of reagent is, gained at introduction of a xylene, toluene and butylacetate. Viscosity of oil decreases at increase in a dosage of reagent. The relaxation of properties after complex processing is characteristic of oil.

On the basis, of the made supervision and studying of nature of impact of cavitation on oil, it is possible to draw a conclusion that cavitation leads to destruction of paraffin and supramolecular structures of oil (associates, micelles) and to reduction of their, size that promotes decrease in viscosity. But eventually, the shattered particles reestablish intermolecular communication that leads to restoration of dynamic viscosity of crude oil.

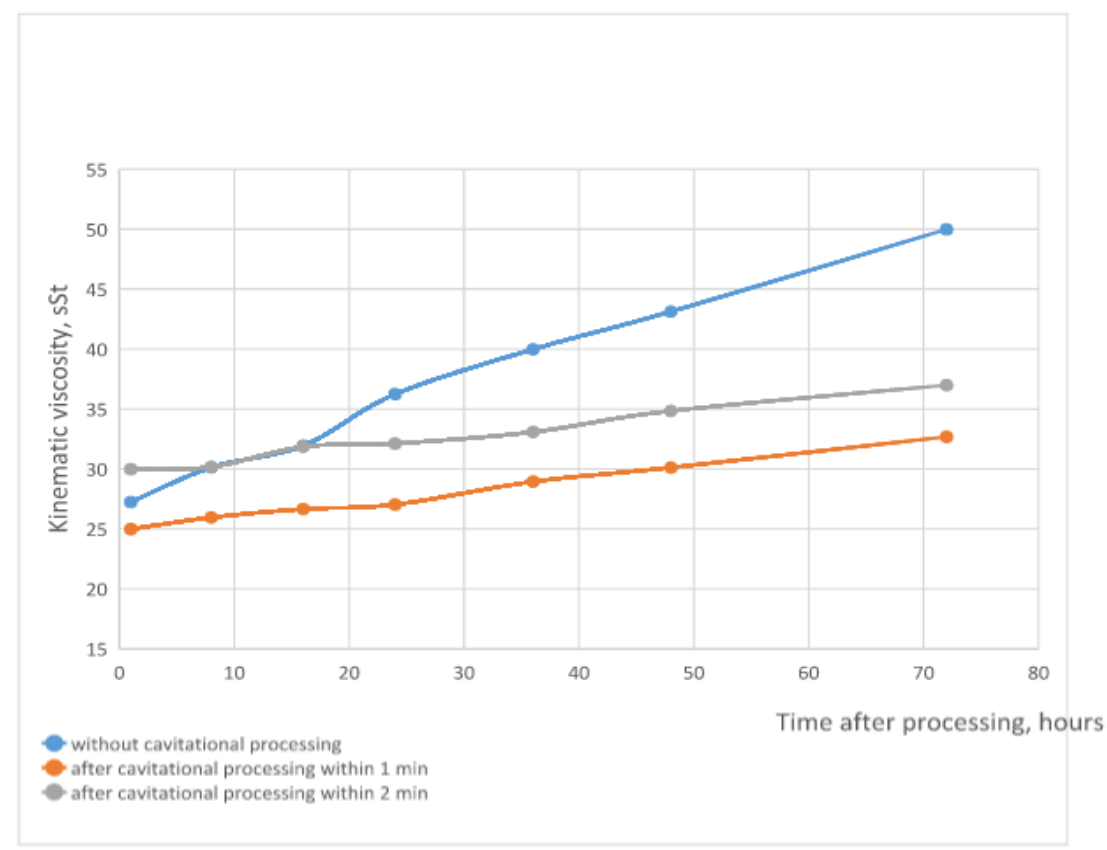

Fig8. Change of kinematic viscosity of oil of the field Shirvan from a test storage time after introduction of $2 \%$ of mass. butylacetate and hashing: 1 - without cavitational processing; 2 - after cavitational processing within 1 min.; 3 -after cavitational processing within 2 min. 


\section{H. Nurullayev et al.}

To identify the impact of reagent "BAF-1 and BAF-2" on kinematic viscosity of commercial oil, the action of the reagent has been tested directly on the oil from Muradkhan's oilfield in static and dynamic conditions, i.e. in conditions of cavitation.

These conditions were established using specially assembled equipment, which was necessary to perform laboratory tests. For this, $300 \mathrm{ml}$ of commercial oil from Muradkhan's oilfield was taken. The measurement of kinematic viscosity of oil was held before and after cavitation.

As can be seen from the Table the highest viscosity reduction is observed without cavitation in quantities of $40 \mathrm{ml}$ of reagent and is $41.86 \mathrm{~mm}^{2} / \mathrm{sec}(48.86 \%)$. The highest reduction of viscosity with cavitation occurs also with $40 \mathrm{ml}$ of reagent and is $32.74 \mathrm{~mm}^{2} / \mathrm{sec}(6075 \%)$. Thus, the viscosity is observed more with cavitation than without cavitation. In both cases the viscosity of oil increases after increasing the amount of reagent to quantities more than $40 \mathrm{ml}$ (Table 2).

Table2. Cavitation effect of chemicals in the process

\begin{tabular}{|c|c|c|c|c|c|c|c|}
\hline \multirow{2}{*}{$\begin{array}{l}\text { Time of cavitation } 15 \mathrm{~min} \\
\text { in the presence of Turrax } \\
\mathrm{T} 25(600 \mathrm{~W}, 50 / 60 \mathrm{~Hz} \text {, } \\
\left.230 \mathrm{~V}, 24000 \mathrm{~min}^{-1}\right)\end{array}$} & \multicolumn{7}{|c|}{$300 \mathrm{ml}$ oil composite volume, $\mathrm{ml}$} \\
\hline & 0 & 10 & 20 & 30 & 40 & 50 & 60 \\
\hline $\begin{array}{l}\text { Kinematic viscosity to } \\
\text { cavitation } \mathrm{mm}^{2} / \mathrm{sec}\end{array}$ & 83,42 & 71,23 & 58,28 & 46,23 & 41,86 & 59,25 & 69,77 \\
\hline $\begin{array}{l}\text { Kinematic viscosity after } \\
\text { cavitation } \mathrm{mm}^{2} / \mathrm{sec}\end{array}$ & 75,93 & 60,58 & 47,62 & 36,84 & 32,74 & 48,97 & 58,82 \\
\hline
\end{tabular}

The trend of dependency of kinematic viscosity oil from Muradkhan's oilfield on the amount of reagent before and after cavitation is clearly visible in the graph (Fig.9)

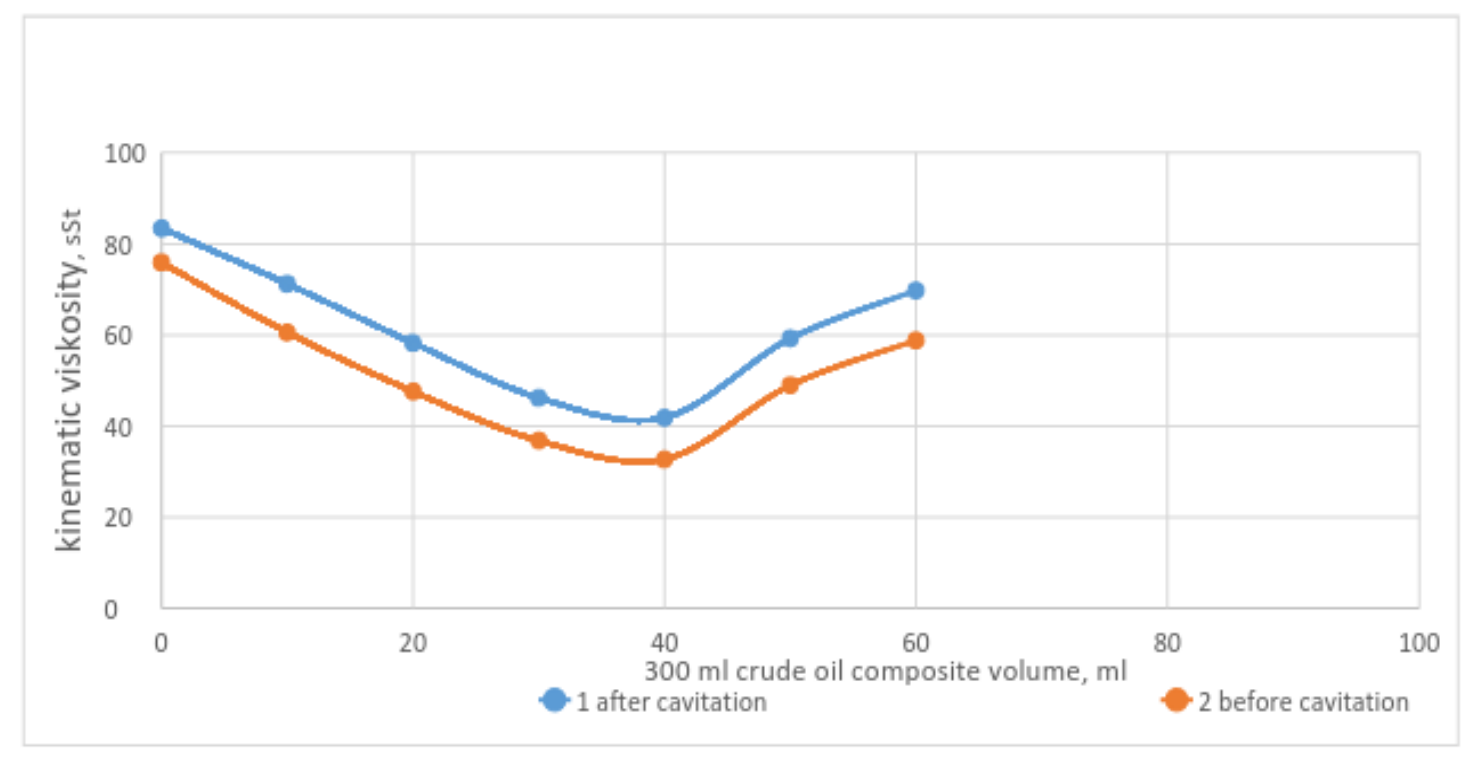

Fig9. Change of kinematic viscosity of crude oil of the field Muradkhanli depending on test processing time

The results of the study show that in the condition with cavitation the action of the reagent on reduction of viscosity is very high.

\section{Conclusion}

On the basis of the made supervision and studying of nature of impact of cavitation on oil, it is possible to draw a conclusion that cavitation leads to destruction of paraffin and supramolecular structures of oil (associates, micelles) and to reduction of their size that promotes decrease in viscosity. But eventually, the shattered particles reestablish intermolecular communication that leads to restoration of dynamic viscosity of crude oil.

Introduction of reagent changes molecular mobility of group components of the oil disperse systems (ODS) and leads to decrease in viscosity and aggregate stability of the ODS.

At complex influence, cavitation allows reagent to influence more effectively group components of oil due to reduction of their size and increase in the area of contact. Reagent interferes with restoration 
of intermolecular communications and formation of supramolecular educations in oil after processing at the expense of what the bigger effect of decrease in viscosity is reached.

\section{ACKNOWLEDGEMENTS}

The authors gratefully acknowledge the research council of State Oil Company of the Azerbaijan Republic and Azerbaijan State University of Oil and Industry.

\section{REFERENCES}

[1] Specialized Training for Oil Tankers, International Maritime Organization, Model Course 1.02, Edition (TB102E), London. 2006.

[2] D. L. Lord, D. K. Rudeen, Strategic Petroleum Reserve Crude Oil Equation of State Model Development - Current Performance Against Measured Data, Research Report, Sandia National Laboratories, Albuquerque, NM \& Livermore, CA. 2010.

[3] Earls Brennen Cavitation and bubble dynamics by Christopher ( $)$ Oxford University Press. 1995, $254 \mathrm{p}$.

[4] A.Y. Isakov, A.A. Isakov. Cavitation of mixing devices: Monograph. - PetropavlovskKamchatsky: Kamchat of STU. 2006, 206 p.

[5] V. A. Yakovlev, S. G. Zavarukhin, V. T. Kuzavov, N. V. Small, L. I. Maltsev, V. N. Parmon. Research of chemical transformations of organic compounds at cavitational influence. Chemical physics, vol. 29, no. 3. 2010, pp. 43-51.

[6] V. H. Nurullayev. The Theoretikal analysis of crude oil vapour pressure and cavitational technologies studying of physical and chemical properties of transported oil in the course of cavitation. Science and applied engineering quarterly. № 5. 2014, pp. 23-29.

[7] M. S, Fomitchev-Zamilov, M.I. Fluid hammers, hydrodynamic sirens, stream reactors, implementation of same, and methods for treatment of fluids. PCT Application \#13/869,017. 2014.

[8] M. S, Fomitchev-Zamilov, M.I. Hydrodynamic siren theory, 2013, http://www.quantumvortex Hydrodynamic no 20, Siren no 20 Theory. pdf.

[9] D. Flanigan, K. Suslick. Internally confined plasma in an imploding bubble, Nature Physics, № 6, 2010, pp. 598-601.

[10] S. Niazi, S. Hasshembadi. CFD Simulation of acoustic cavitation in a crude oil upgrading sonoreactor and prediction of collapse temperature and pressure of a cavitation bubble. Chemical Engineering Research and Design, in press. № 6. 2013. pp.37-42.

[11] A.S. Besov, et al. Degradation of Hydrocarbons in the Cavitation Region Activated by Aqueous Electrolyte Solutions in the Presence of Electric Field, Technical Physics Letter. № 3. vol. 29, 2003, pp. 207-209.

[12] A. Chakma, F. Berruti,. The Effects of Ultrasonic Treatment on the Viscosity of Athabasca Bitumen and Bitumen-solvent Mixtures, The Journal of Canadian Petroleum Technology. № 5, vol. 32, 1993, p. 48-53.

[13] V. H. Nurullayev, S. T. Aliyev. About prospects of application of cavitational technologies during the transporting and oil refining. News of the highest technical educational institutions of Azerbaijan. №. 5 vol.75, 2011, pp. 23-28

[14] B. T. Usubaliyev, E.E. Ramazanova V.H. Nurullayev, F.S. Gehremanov F.B. Aliyeva. Use nanostructured the coordination compounds to reduce the viscosity of transported heavy tank oil. Problems of gathering, treatment and transportation of oil and oil products, № 3 , vol. 101. 2015, pp. 117-126.

[15] M. A. Yershov, D. A. Rams, M. S. Mullakayev, V.O. Abramov. Decrease in viscosity paraffinic oil in the ultrasonic field. Chemical and oil and gas mechanical engineering. № 7, 2011.pp 16-19.

[16] V. H. Nurullayev, G.G. Ismayilov. Transport crude oil with application of cavitational technologies and determination of density taking into account water content //Transport and storage of oil products and hydrocarbons. 2015. № 1. pp. 7-11.

[17] M. A. Promotov. Cavitational technology of improvement of quality of hydrocarbonic fuels // Chemical and oil and gas mechanical engineering. № 2, 2008. pp. 6-12. 